\title{
Parvalbumin Cell Ablation of NMDA-RI Causes Increased Resting Network Excitability with Associated Social and Self-Care Deficits
}

\author{
Eddie N Billingslea', Valerie M Tatard-Leitman', Jaynie Anguiano', Catherine R Jutzeler', Jimmy Suh', \\ John A Saunders', Susumu Morita', Robert E Featherstone', Pavel I Ortinski', Michael J Gandal', \\ Robert Lin', Yuling Liang', Raquel E Gur', Gregory C Carlson', Chang-Gyu Hahn' and Steven J Siegel*,' \\ 'Department of Psychiatry, University of Pennsylvania, Philadelphia, PA, USA
}

\begin{abstract}
NMDA-receptor (NMDAR) hypofunction is strongly implicated in the pathophysiology of schizophrenia. Several convergent lines of evidence suggest that net excitation propagated by impaired NMDAR signaling on GABAergic interneurons may be of particular interest in mediating several aspects of schizophrenia. However, it is unclear which behavioral domains are governed by a net increase of excitation and whether modulating downstream GABAergic signaling can reverse neural and thus behavioral deficits. The current study determines the selective contributions of NMDAR dysfunction on PV-containing interneurons to electrophysiological, cognitive, and negative-symptom-related behavioral phenotypes of schizophrenia using mice with a PVcre-NRIflox-driven ablation of NRI on PV-containing interneurons. In addition, we assessed the efficacy of one agent that directly modulates GABAergic signaling (baclofen) and one agent that indirectly modifies NMDAR-mediated signaling through antagonism of mGluR5 receptors (2-methyl-6-(phenylethynyl) pyridine (MPEP)). The data indicate that loss of NMDAR function on PV interneurons impairs self-care and sociability while increasing N I latency and baseline gamma power, and reducing induction and maintenance of long-term potentiation. Baclofen normalized baseline gamma power without corresponding effects on behavior. MPEP further increased NI latency and reduced social behavior in PVcre/ $\mathrm{NRI}+/+$ mice. These two indices were negatively correlated before and following MPEP such that as NI latency increases, sociability decreases. This finding suggests a predictive role for NI latency with respect to social function. Although previous data suggest that MPEP may be beneficial for core features of autism spectrum disorders, current data suggest that such effects require intact function of NMDAR on PV interneurons.

Neuropsychopharmacology (2014) 39, I603-16I3; doi:I0.I038/npp.2014.7; published online 26 March 2014
\end{abstract}

\section{INTRODUCTION}

Schizophrenia is a devastating disorder that affects $\sim 1 \%$ of the world's population. Core features of schizophrenia are classified into positive symptoms (eg, hallucinations and delusions) or negative symptoms (eg, anhedonia, alogia, social apathy, and poor self-care). NMDA-receptor (NMDAR) hypofunction is strongly implicated in the pathophysiology of the latter aspects of the disorder (Javitt et al, 1994; Krystal et al, 1994). In addition, we and others have previously demonstrated that NMDAR antagonists, such as MK-801 and ketamine, recreate many of the electroencephalographic (EEG) frequency and event-related

\footnotetext{
*Correspondence: Dr SJ Siegel, Room 2202, Translational Research Laboratories, University of Pennsylvania, $125 \mathrm{~S} 3$ I st Street, Philadelphia, PA 19104, USA, Tel: + I 215573 0278, Fax: + I 215573 2041, E-mail: siegels@upenn.edu

Received 18 June 2013; revised 28 October 2013; accepted 28 October 2013; accepted article preview online 14 February 2014
}

potential (ERP) abnormalities of schizophrenia (Connolly et al, 2004; Featherstone et al, 2012; Krystal et al, 1994; Lahti et al, 1995; Maxwell et al, 2006). These include reduced N1 amplitude, disruption of novelty-related mismatch negativity, as well as alterations in gamma oscillations (Ehrlichman et al, 2008; Lazarewicz et al, 2010). NMDAR antagonists also disrupt cognitive measures such as contextual fear conditioning and novel object recognition in rodents (Amann et al, 2009; Featherstone et al, 2012). Previous data from our group demonstrate that constitutive reduction of the obligatory NMDAR subunit NR1 leads to abnormalities consistent with negative symptoms, such as reduced social interactions and nest building (Gandal et al, 2012). Additional previous preclinical and clinical studies also suggest that there is a net increase in overall brain activity following experimental disruptions of NMDAR signaling in both rodents and people with schizophrenia (Gandal et al, 2012). These data suggest that disruption of NMDAR function results in either a net reduction of inhibition or an increase in excitation. 
Reduction of NMDAR function on GABAergic interneurons could yield a complex pattern of decreased inhibition resulting in net excitation in the brain. Several convergent lines of evidence have suggested that net excitation propagated by impaired NMDAR signaling on GABAergic interneurons may be of particular interest in mediating several aspects of schizophrenia. However, it is unclear which behavioral domains are governed by a net increase of excitation and whether modulating downstream GABAergic signaling can reverse neural and thus behavioral deficits. Although a host of indirect pharmacological and optogenetic evidence have implicated a selective role for reduced NMDAR function on parvalbumin-containing interneurons in schizophrenia, there is relatively little direct evidence to support that supposition (Carlen et al, 2012; Yizhar et al, 2011). Therefore, a better understanding of these signaling processes will be informative for determining which pharmacological countermeasures would be expected to ameliorate each symptom or dysfunctional area.

The current study determines the selective contributions of NMDAR dysfunction on PV-containing inhibitory interneurons to electrophysiological, cognitive, and negativesymptom-related behavioral phenotypes of schizophrenia. To this end, mice with a PVcre-NR1flox-driven ablation of NR1 on PV-containing interneurons were used. In addition, we assessed the ability of agents that share pharmacological specificity with drugs that are currently in clinical trials for treatment of social and communicative deficits to reverse negative symptom model behaviors in these mice. These include one agent that directly modulates GABAergic signaling (baclofen) and one agent that indirectly modifies NMDAR-mediated signaling through antagonism of metabotropic glutamate receptor 5 (mGluR5) receptors (2-methyl-6-(phenylethynyl) pyridine (MPEP)).

\section{MATERIALS AND METHODS}

\section{Subjects}

Homozygous Parvalbumin-cre/cre mice (B6;129P2-Pvalbtm1 (cre)Arbr/J) as well as homozygous NMDA-Receptor $1_{\text {flox/flox }}$ mice (B6.129S4-Grin1tm2Stl/J) were purchased from The Jackson Laboratory (Bar Harbor, ME). Animals were housed in temperature-controlled rooms with a 12-h light/12-h dark cycle (lights on at $0700 \mathrm{~h}$ ). They were given TestDiet 5001 (Purina Mills, Richmond, IN) and water ad libitum. Cages were changed weekly. All animal procedures were in strict accordance with the National Institutes of Health Guide for the Care and Use of Laboratory Animals and were approved by the University of Pennsylvania Institutional Animal Care and Use Committee.

\section{Breeding Strategy}

Mice with a cell type and regionally controllable deletion of the NMDAR1 subunit were purchased from The Jackson Laboratory (strain name: B6.129S4-Grin1 $1^{\text {tm } 2 S t l} / \mathrm{J}$ ). These mice possess loxP sites flanking $\sim 12 \mathrm{~kb}$ of sequence of the targeted gene that encodes the entire transmembrane domain and C-terminal region (flanked by loxP $=$ floxed). A targeting vector containing the gene sequence, neomycin resistance, and thymidine kinase genes was utilized in the construction of this mutant. The construct was electroporated into 129S4/SvJae-derived J1 embryonic stem (ES) cells. Correctly targeted ES cells were injected into C57BL/6 blastocysts. The resulting chimeric animals were crossed to C57BL/6J mice, and backcrossed to the same for eight generations (Capecchi, 1989; Tsien et al, 1996). Mice that are homozygous for this allele are viable, fertile, normal in size, and do not display any gross physical or behavioral abnormalities (Tsien et al, 1996). Restriction of the knockout of NMDA receptors on corticolimbic parvalbumincontaining interneurons was accomplished using a mosaic transgenic approach by breeding NR1 $1^{\text {flox }}$ mice with transgenic mice expressing selective expression of a Cre activator in parvalbumin-containing interneurons. Groups will be composed of mice with 0 (NR1-I-), $1(\mathrm{NR} 1+/-)$, or 2 $(\mathrm{NR} 1+I+)$ working copies of NR1 in PV cells. This strain expresses Cre recombinase from the endogenous Pvalb, parvalbumin locus. When crossed with a strain containing loxP site flanked sequence, Cre-mediated recombination results in cell type-specific deletion of the target. Recombination occurs in $>90 \%$ of CNS interneurons that express parvalbumin (Hippenmeyer et al, 2005). An IRES-Cre-pA targeting cassette containing cre coding sequence, internal ribosome entry site (IRES), and polyadenylation site sequence was inserted into the $3^{\prime}$ UTR of exon 5 . The endogenous Pvalb promoter drives expression of the Cre recombinase. The construct was electroporated into 129P2/ OlaHsd-derived E14 ES cells. Correctly targeted ES cells were injected into recipient blastocysts. Resulting chimeric animals were crossed to C57BL/6 mice. Heterozygotes were intercrossed to produce homozygotes (Hippenmeyer et al, 2005). Subjects came from the F3 generation (highlighted in gray in Supplementary Table 1).

\section{RNA Analysis}

RNAs were purified using Trizol. High-Capacity cDNA Reverse Transcription Kit (Applied Biosystems) was used for reverse transcription, using protocols and methods as recommended by the manufacturer. QPCR was performed using Power SYBR Green PCR Master Mix (Applied Biosystems, Carlsbad, CA) using protocols and methods as recommended by the manufacturer. The following primers were used: NR1-A: 5'-CCTTCTACCAAGGGCTATGATG-3' and NR1-B: 5'-AACAAACAATGCTGAGGTGGTAG-3'.

\section{Behavioral Testing}

Nest building. Assessment of nest building was performed as previously described (Deacon, 2006). Briefly, mice housed in groups were transferred to single cages containing clean bedding at $\sim 1 \mathrm{~h}$ before the dark cycle. To each cage, $3 \mathrm{~g}$ of nonshredded nestlet was added. The weights of nonshredded nestlet as well as the dispersion of nestlet pieces in the cage were determined. A score of zero was given to a nonshredded nestlet, whereas a score of 5 was given to a fully shredded, nondispersed nestlet.

Social interaction. Social behavior was assessed using a social preference test as previously described (Sankoorikal et al, 2006). Social approach of test mice was measured toward same sex gonadectomized DBA/2J stimulus mice to 
minimize aggressive and sexual motivations of the test mouse toward the stimulus mouse. Test and stimulus mice were brought to the testing room in their home cages for a habituation period of $\sim 30 \mathrm{~min}$ before starting the test. All behavioral tests were run in red light and videotaped. A testing apparatus with three interconnected chambers was used with a clean mat and clean bedding. Two identical clear cylinders with small holes were placed one in each end chamber. A stimulus mouse was placed in one of the cylinders (social cylinder) whereas the other cylinder remained empty (nonsocial cylinder). The test mouse was transferred to the middle chamber and allowed to explore the apparatus for $5 \mathrm{~min}$. The time spent in each chamber as well as the number of times the test mouse entered each chamber were calculated. The apparatus was thoroughly cleaned between each test.

Spontaneous T-maze alternation. Spatial working memory was assessed using both continuous and discrete T-maze paradigms. Mice were brought to the test room $30 \mathrm{~min}$ before testing to acclimate. For both T-maze versions, soiled bedding from the opposite sex was placed in the maze. The bedding was changed between each set of trials. Mice were tracked with an overhead video camera and manually scored. Both versions of T-maze trials were performed as previously described (Deacon and Rawlins, 2006). Briefly, for the continuous trials, each individual mouse was placed in the start arm of the maze and its alternations among the three arms were recorded for $8 \mathrm{~min}$. A mouse was scored as having entered an arm when all four paws were located within the runway. An alternation was defined as sequential entries into each of the three different arms (eg, $\mathrm{ABC}, \mathrm{BCA}$, and so on). Spontaneous alternation percentage was calculated as the total number of alternations divided by (total arm entries minus 2). For the discrete trials, all three doors of the maze were raised and the central partition put in place. Each individual mouse was placed at the end of the start arm facing away from goal arms. Once the mouse had reached the goal arm, the door was shut and the mouse was left to explore for $10 \mathrm{~s}$. During this time, the central partition was removed, and a partition was placed in the center arm. The mouse was then returned to the start arm. All doors were raised and the mouse was allowed to choose between the two opened goal arms. A cutoff time of $90 \mathrm{~s}$ was used for sample or choice runs. The mouse was considered to have alternated if it had chosen the opposite arm as the one chosen during the previous run.

Open field. Animals were allowed to habituate for $30 \mathrm{~min}$ in the room before starting the test. They were transferred to a new home cage environment placed inside an automated locomotor activity photobeam frame (30, 24, $8 \mathrm{~cm}$ ) with sensors arranged in an 8-beam array strip with $3.175 \mathrm{~cm}$ spacing (MED Associates, St Albans, VT). The bedding was changed and the cage cleaned between each mouse. The test ran for $30 \mathrm{~min}$ during which the total distance traveled as well as the time spent in the center of the cage were recorded by computer using the MED PC software set to record the number of times that horizontal light beams were broken.

\section{Drug Studies}

For behavioral measures and electrophysiological indices in which deficits existed in PVcre/NR1fl/fl mice relative to $\mathrm{PVcre} / \mathrm{NR} 1+/+$ mice, groups were retested following administration of either mGluR5 antagonist MPEP (20 mg/ $\mathrm{kg}$, Tocris, Minneapolis, $\mathrm{MN}$ ) or $\mathrm{GABA}_{\mathrm{B}}$ receptor agonist baclofen $(2.5 \mathrm{mg} / \mathrm{kg}$, Sigma, St Louis, MO), drugs that have been shown to ameliorate aberrant social phenotypes in other mouse models relevant to schizophrenia and/or ASD (Gandal et al, 2010; Gandal et al, 2012).

\section{In Vivo Electrophysiology}

EEG/ERP recording. Animals were anesthetized with isoflurane and underwent stereotaxic implantation of tripolar electrode assemblies (PlasticsOne, Roanoke, VA). Low-impedance stainless steel macroelectrodes $(<5 \mathrm{k} \Omega$, $1000 \mathrm{~Hz}$ ) were aligned along the sagittal axis of the skull at $1 \mathrm{~mm}$ intervals (anterior to posterior: negative-groundpositive). The electrodes were precut with a length of $3 \mathrm{~mm}$ (positive) and $1 \mathrm{~mm}$ (ground and negative). The positive electrode was placed $1.8 \mathrm{~mm}$ posterior, $2.65 \mathrm{~mm}$ right lateral, and $2.75 \mathrm{~mm}$ deep relative to Bregma. The electrode pedestal was secured to the skull with ethyl cyanoacrylate (Loctite; Henkel, Westlake, $\mathrm{OH}$ ) and dental cement (Ortho Jet; Lang Dental, Wheeling, IL). This recording paradigm can replicate clinical auditory ERP findings in humans that are primarily sourced to the cortex (Carlson et al, 2011; Ehrlichman et al, 2009; Gandal et al, 2008; Halene et al, 2009; Lazarewicz et al, 2010). Recording of auditory ERPs was performed on awake mice at least 1 week after electrode implantation, in a home cage environment, as previously described (Ehrlichman et al, 2009; Gandal et al, 2008; Halene et al, 2009; Lazarewicz et al, 2010). Mice were brought to the room $30 \mathrm{~min}$ before recording for acclimation. Cages were placed in a sound-attenuated recording chamber located inside a Faraday electrical isolation cage. Electrode pedestals were connected to a $30 \mathrm{~cm}$ tripolar electrode cable that exited the chamber to connect to a high impedance differential AC amplifier (A-M Systems, Carlsborg, WA). Stimuli were generated by Micro1401 hardware with Spike2 software (Cambridge Electronic Design, Cambridge, UK) and were delivered through speakers attached to the cage top. The sequencer file consisted of a series of 200 broadband white-noise stimuli, $10 \mathrm{~ms}$ in duration, presented at $85 \mathrm{~dB}$ with an 8 -s interstimulus (ISI) interval. We analyzed data capture during the 8-s ISI, as this interval allows for a complete return to resting activity after stimulus onset. Raw EEG was filtered between 1 and $500 \mathrm{~Hz}$. Individual sweeps were rejected for movement artifact based on a criterion of 2 times the root mean squared amplitude per mouse. The amplitude and latency of the N40 was defined by the point of maximum negative deflection following the P20 (first major positive deflection) as shown in Supplementary Figure 2 and previously published (Connolly et al, 2004; Ehrlichman et al, 2008; Featherstone et al, 2012; Featherstone et al, 2013; Halene et al, 2009). Although the N40 typically falls between 30 and $80 \mathrm{~ms}$ in wild-type mice, this range was extended to incorporate the appropriate point among all mice in the study. 
Signal processing. Time-frequency decomposition of EEG signal was performed with the EEGLAB toolbox in Matlab (Delorme and Makeig, 2004). Single trial epochs between -0.4 and $0.8 \mathrm{~s}$ relative stimulus onset were extracted from the continuous data sampled at $1667 \mathrm{~Hz}$. Baseline power and evoked (ie, phase locked) power were calculated using Morlet wavelets in 100 linearly spaced frequency bins between 5 and $100 \mathrm{~Hz}$, with wavelet cycles linearly increasing from 3 to 6 , and a pad-ratio of 16 , as previously published (Gandal et al, 2010). For each subject, evoked power was averaged from 0 to $200 \mathrm{~ms}$ after stimulus in the gamma frequency ranges (30$80 \mathrm{~Hz}$ ). Prestimulus total power was calculated in the same frequency ranges from -299 to $-100 \mathrm{~ms}$ relative to the stimulus onset. Finally, gamma signal-to-noise ratio (SNR) was calculated as the maximal peak in the poststimulus gamma-band response from 0 to $500 \mathrm{~ms}$ divided by the average prestimulus gamma power.

\section{Ex Vivo Electrophysiology}

Hippocampal slice preparation. Mice were decapitated following isoflurane anesthesia. The brain was removed and coronal slices $(300 \mu \mathrm{m})$ containing the hippocampus were cut with a Vibratome (VT1000S, Leica Microsystems, Solms, Germany) in an ice-cold artificial cerebrospinal fluid solution (ACSF) in which $\mathrm{NaCl}$ was replaced by an equiosmolar concentration of sucrose. ACSF consisted of $130 \mathrm{mM} \mathrm{NaCl}, 3 \mathrm{mM} \mathrm{KCl}, 1.25 \mathrm{mM} \mathrm{NaH} \mathrm{PO}_{4}, 26 \mathrm{mM}$ NaHCO3, $10 \mathrm{mM}$ glucose, $1 \mathrm{mM} \mathrm{MgCl} 2$, and $2 \mathrm{mM} \mathrm{CaCl}_{2}$ ( $\mathrm{pH}$ 7.2-7.4 when saturated with $95 \% \mathrm{O}_{2} / 5 \% \mathrm{CO}_{2}$ ). Slices were incubated in ACSF at $32-34{ }^{\circ} \mathrm{C}$ for $45 \mathrm{~min}$ and kept at $22-25^{\circ} \mathrm{C}$ thereafter, until transfer to the recording chamber. The osmolarity of all solutions was 305$315 \mathrm{mOsm}$. Slices were viewed using infrared differential interference contrast optics under an upright microscope (Eclipse FN1, Nikon Instruments, Melville, NY) with a $40 \times$ water-immersion objective.

Ex vivo recording. The recording chamber was continuously perfused $(1-2 \mathrm{ml} / \mathrm{min})$ with oxygenated ACSF heated to $32 \pm 1{ }^{\circ} \mathrm{C}$ using an automatic temperature controller (Warner Instruments, Hamden, CT).

Patch clamp studies. For patch studies, picrotoxin $(100 \mu \mathrm{M})$ was added to all solutions to block the $\mathrm{GABA}_{\mathrm{A}}$ receptormediated currents. The intracellular solution contained (in $\mathrm{mM}$ ): 145 potassium gluconate, $2 \mathrm{MgCl}_{2}, 2.5 \mathrm{KCl}, 2.5 \mathrm{NaCl}$, 0.1 BAPTA, 10 HEPES, 2 Mg-ATP, 0.5 GTP-Tris ( $\mathrm{pH}$ 7.2-7.3 with $\mathrm{KOH}$, osmolarity 280-290 mOsm). Recordings were performed in whole-cell voltage-clamp $(\mathrm{Vh}=-65 \mathrm{mV})$ or whole-cell current-clamp (at resting potential) modes as indicated. The data were acquired through a MultiClamp700B amplifier (Molecular Devices, Sunnyvale, CA). Currents were low-pass filtered at $2 \mathrm{kHz}$ and digitized at $20 \mathrm{kHz}$ using a Digidata $1440 \mathrm{~A}$ acquisition board and pClamp10 software (both from Molecular Devices). Access resistance was monitored throughout the recordings by injection of $10 \mathrm{mV}$ hyperpolarizing pulses (in voltageclamp) and data were discarded if the access resistance changed by $>25 \%$ over the course of data acquisition. Evoked responses were triggered by constant-current pulses generated by an A310 Accupulser (World Precision Instruments, Sarasota, FL) and delivered at $0.2 \mathrm{~Hz}$ via a bipolar tungsten stimulation electrode positioned within $100 \mu \mathrm{m}$ of the recorded cell. The amplitude of the current pulses was controlled by a stimulus isolator (ISO-Flex, A.M.P.I., Jerusalem, Israel) and was adjusted in each cell to evoke a minimal response with a $25 \mu \mathrm{s}$ current pulse. The current duration was then increased to $50,75,100$, and $125 \mu$ s to construct an input-output curve for the evoked synaptic events.

LTP studies. For long-term potentiation (LTP) studies, evoked responses were triggered by constant-current pulses generated by an A310 Accupulser (World Precision Instruments) and delivered at $50 \%$ of maximum stimulus via a bipolar tungsten stimulation electrode positioned within $100 \mu \mathrm{m}$ of the recording electrode. Baseline stimulation was recorded for $15 \mathrm{~min}$ before onset of tetanus. Tetanus was induced by giving two $100 \mathrm{~Hz}$ pulses $10 \mathrm{~s}$ apart. LTP was recorded for $1 \mathrm{~h}$.

Data analysis and statistics. All analyses of intracellular recordings were carried out with Clampfit 10 (Molecular Devices). The time constant of decay was based on a monoexponential fit to the decay phase of an average spontaneous excitatory postsynaptic current (sEPSC) trace computed from a minimum of 50 individual sEPSCs. Mean sEPSC frequencies were analyzed from 10 to $20 \mathrm{~s}$ long trace segments. Evoked EPSC amplitudes were computed from an average of 5-10 responses at each stimulation intensity. Membrane capacitance was calculated from a transient current response to a depolarizing $10 \mathrm{mV}$ pulse. Input resistance (Rin) was computed from a linear portion of the I-V plot in response to $500 \mathrm{~ms}$ current steps from -200 to $+400 \mathrm{pA}$. Rheobase was measured as the minimal current (advanced in $10 \mathrm{pA}$ steps) necessary to trigger an action potential. Spike height was calculated as the difference between the spike threshold (measured on response to the smallest current step triggering an action potential) and the spike peak. Spike half-width was measured at the half-height between spike threshold and spike peak. Afterhyperpolarization (AHP) was defined as the difference between spike threshold and the peak of the negative potential after the spike. Statistical analyses were performed with Microsoft Excel for Windows software. Statistical comparisons were done using independent Student's $t$-tests or repeated measures two-way ANOVA as indicated. All data are expressed as mean \pm SEM.

\section{RESULTS}

\section{Characterization of PV Interneuron-Specific NMDA-R1 Knockout Mice}

We performed PV immunostaining in transgenic PVcre; (td)TomatoFlox mice in which the expression of the red fluorescent protein (td)Tomato is restricted to PVcreexpressing cells. PV immunolabeling was observed in all (td)Tomato-positive cells, demonstrating that recombination occurred in only PV-positive interneurons (Supplementary Figure 1). 


\section{Behavioral Results}

Self-care behavior. Nest building was investigated as a feature relevant to self-care. PVcre/NR1fl/fl mice showed a significant nest-building deficit compared with PV cre/ $\mathrm{NR} 1+I+$ mice $(t=2.117, \mathrm{df}=22, p<0.04) . \mathrm{PV}$ cre/NR1 $+I+$ mice built adequate nests of shredded nestlet, whereas PVcre/NR1fl/fl mice built less complete nests containing large pieces of intact nestlet (Figure 1a).

Social interactions. Sociability was tested in PVcre/NR1fl/ $\mathrm{fl}$ and PVcre/NR1 + / + littermates using a social index score. PVcre/NR1fl/fl animals had significantly lower social index scores, and therefore spent significantly less time with the novel conspecific target mouse than the PVcre/NR1 $+/+$ animals $(73.3$ vs $58.7 \%, t=3.44, \quad \mathrm{df}=19, \quad p=0.002$; Figure 1b).

Cognitive behaviors. Cognition was tested using discreet and continuous T-maze paradigms. There was no difference in performance between PVcre/NR $1+I+$ and PVcre/ NR1fl/fl mice on the discrete T-maze task. Conversely, PVcre/NR1fl/fl mice performed significantly better than PVcre/ $\mathrm{NR} 1+I+$ mice in the continuous T-maze task $(t=-2.267$, $\mathrm{df}=19, p=0.03)$, indicative of an enhanced working memory in the conditional knockout mice (Figure 1c).

Anxiety-like behavior. Open field activity was measured to assess anxiety-like behavior. We evaluated the percentage of time spent in the center of the apparatus as an indirect measure of anxiety. Furthermore, we used the total distance traveled to evaluate a locomotor measure of hyperactivity. There were no group differences in total distance traveled or time spent in the center in the open field analysis, suggesting that PVcre/NR1fl/fl animals did not exhibit an alteration in either anxiety-like behaviors or hyperactivity (Figure 1d and e).
In vivo electrophysiology. We measured EEG activity using auditory ERPs (Supplementary Figure 2). The auditory stimuli were presented every $8 \mathrm{~s}$ to allow stimulated networks to return to baseline levels of activity between trials. PVcre/NR1fl/fl mice exhibited a significant delay in N1 latency of the ERP waveform compared with PVcre/NR $1+I+$ mice $(t=-7.179, \mathrm{df}=14, p<0.000005)$, similar to the pattern seen in autism spectrum disorders but not schizophrenia (Figure 2a). There was also a trend toward increased $\mathrm{N} 1$ amplitude in the PVcre/NR1fl/fl mice compared with PVcre/NR1 $+/+$ mice $(t=2.129, \mathrm{df}=14$, $p=0.051)$ that is inconsistent with the pattern of reduced $\mathrm{N} 1$ amplitude in schizophrenia (Figure 2b) (Boutros et al, 2009; Turetsky et al, 2008). We then evaluated the relationship between $\mathrm{N} 1$ latency and behavioral measures as N1 delays were implicated in mice that also had deficits in ultrasonic vocalizations, and correlated with language ability in children with ASD (Roberts et al, 2010; Saunders et al, 2013). Data indicated a significant negative correlation between $\mathrm{N} 1$ latency and social index scores $\left(r^{2}=0.3069, p=0.02\right)$; as N1 latency increased, social index scores decreased (Figure 2c). However, there was no correlation between $\mathrm{N} 1$ latency and T-maze performance (Figure 2d).

We next examined the spectral EEG power during auditory stimulation. As previous studies reveal an increase in baseline and a reduction in evoked gamma band power in schizophrenia, we performed an FFT baseline gamma power analysis in both PVcre/NR1fl/fl and PVcre/NR1 $+/+$ mice (Supplementary Figure 3). The analysis indicated a significant increase in baseline gamma power output between 60 and $120 \mathrm{hz}$ in $\mathrm{PVcre} / \mathrm{NR} 1 \mathrm{fl} / \mathrm{fl}$ mice relative to PVcre/ $\mathrm{NR} 1+I+$ mice $(t=-2.370, \mathrm{df}=26, p=0.02$; Figure $2 \mathrm{e})$. However, there was no significant difference in evoked gamma power between PVcre/NR1 $+/+$ and PVcre/NR1fl/fl mice within this range (Figure $2 \mathrm{f}$ ). We next determined whether there was a correlation between baseline and
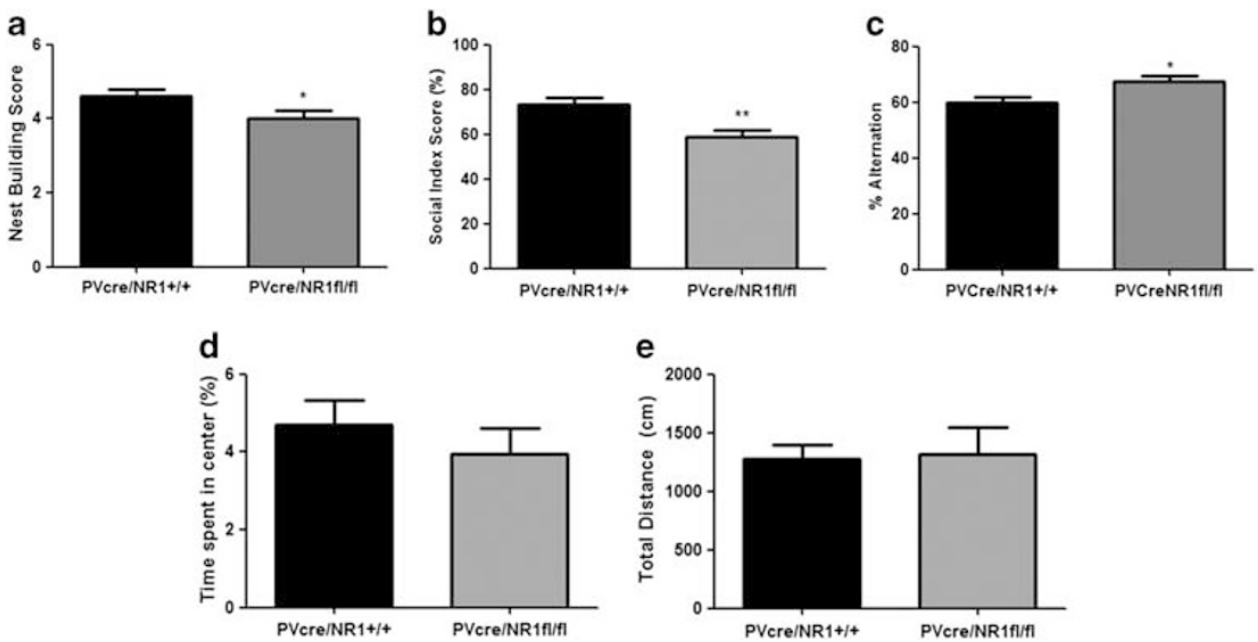

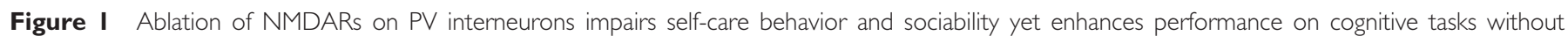

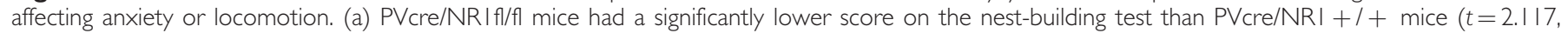

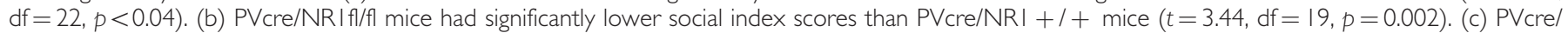

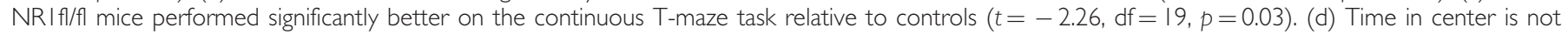

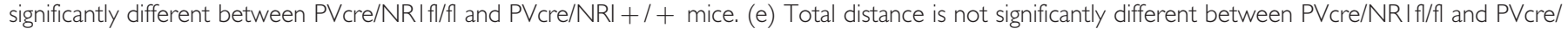
$\mathrm{NRI}+1+$ mice. ${ }^{*} p<0.05$, ** $p<0.01$. 

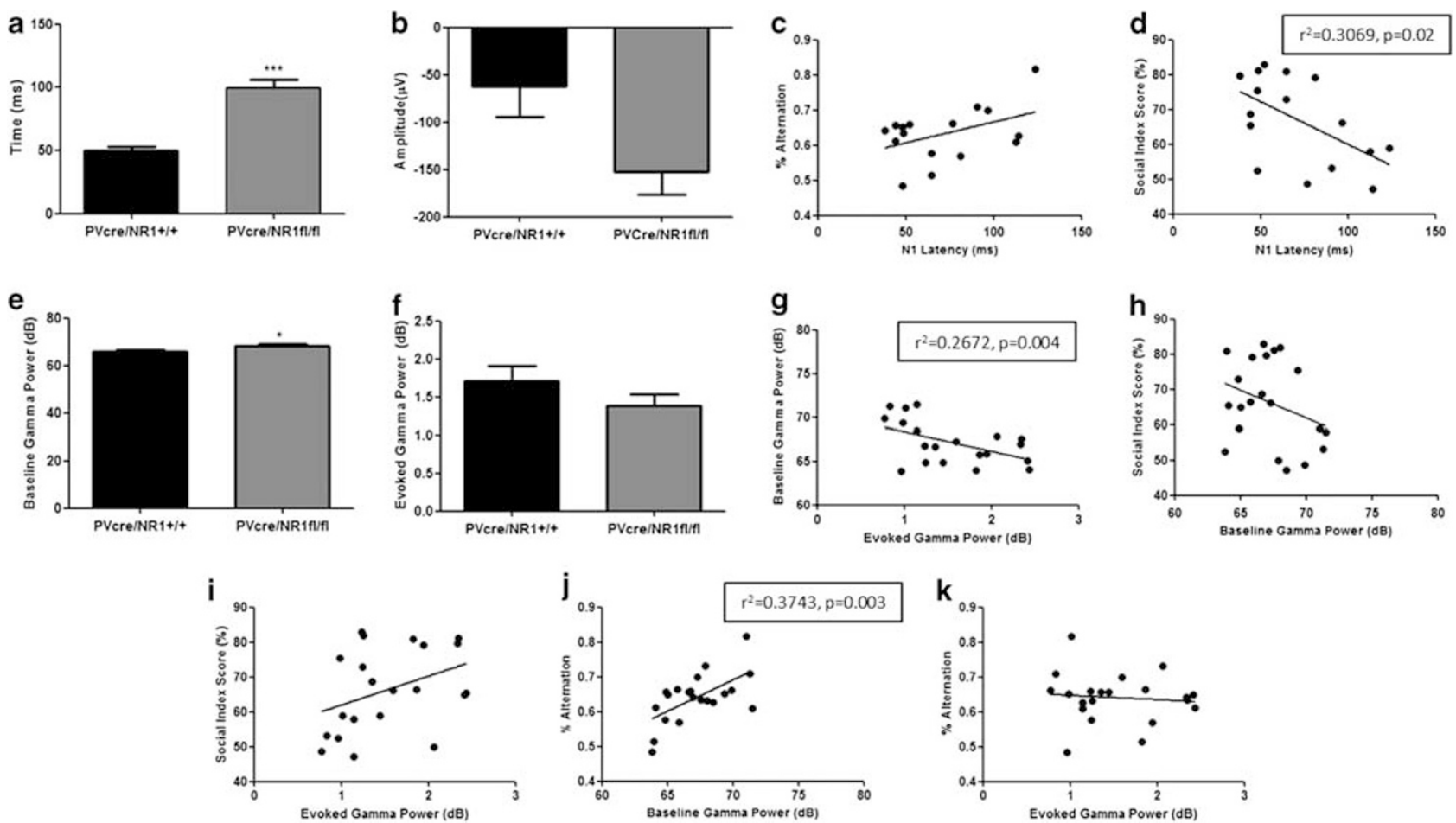

Figure 2 Loss of NMDARs on PV-positive interneurons results in increased baseline gamma power and NI latency. (a) NI latency is significantly increased in PVcre/NRIfl/fl mice relative to PVcre/NRI $+1+$ mice $(t=-7.179, \mathrm{df}=\mid 4, p<0.000005)$ and $\mathrm{NI}$ amplitude trends toward increasing in $P V$ cre/NRIfl/fl mice relative to controls $(t=2.129, \mathrm{df}=14, p=0.05 \mathrm{I})$. (c, d) NI latency is not correlated with (c) cognition; however, there is a significant negative correlation between $\mathrm{NI}$ latency and $(\mathrm{d})$ sociability $\left(r^{2}=0.3069, p=0.02\right)$. (e) Baseline gamma power is significantly higher in PVcre/NRI fl/fl relative to $\mathrm{PV} c r e / \mathrm{NRI}+I+$ mice $(t=-2.37, \mathrm{df}=26, p=0.02)$. The data show evoked gamma power was not significantly different between PVcre/NRI $+I+$ and PVcre/NRIfl/f mice. (g) Data indicate a significant negative correlation between baseline and evoked gamma power $\left(r^{2}=0.2672, p=0.004\right)$. ( $h$, i) Sociability was not correlated with either ( $h$ ) baseline gamma power or (i) evoked gamma power. (j, k) Cognition was significantly correlated with (j) baseline gamma power $\left(r^{2}=0.3743, p=0.003\right)$, but there was no correlation between $(k)$ cognition and evoked gamma power. $* p<0.05$, $* * * p<0.001$.

evoked gamma power, as this association has been demonstrated in several previous studies of both humans and preclinical models of schizophrenia (Hugdahl et al, 2009; Winterer et al, 2000). There was a significant negative correlation between baseline and evoked gamma power $\left(r^{2}=0.2672, p=0.004\right)$, demonstrating that as baseline power increases, evoked power decreases (Figure $2 \mathrm{~g}$ ). In light of this finding, we evaluated the relationship between baseline and evoked power with cognition and social interactions. Data indicate that neither baseline gamma power nor evoked gamma power was correlated with social index scores (Figure $2 \mathrm{~h}$ and $\mathrm{i}$ ). Data also indicate that baseline gamma power was significantly correlated with T-maze performance $\left(r^{2}=0.3743, p=0.003\right)$; as baseline gamma power increases, cognitive performance increases (Figure $2 \mathrm{j}$ ). However, no correlation exists between T-maze performance and evoked gamma power (Figure $2 \mathrm{k}$ ).

Ex vivo electrophysiology. In the patch studies, no significant differences were found between PVcre/NR1fl/fl and PVcre/NR1 $+/+$ mice in evoked amplitude (eEPSCs) or spontaneous (sEPSCs) amplitude or frequency of excitatory postsynaptic currents (Figure 3a-c). However, induction and maintenance of LTP were reduced in PVcre/ NR1fl/fl mice (Figure 3d-f). Upon tetanic stimulation, the average firing of $\mathrm{PVcre} / \mathrm{NR} 1 \mathrm{fl} / \mathrm{fl}$ mice was significantly reduced compared with that of $\mathrm{PVcre} / \mathrm{NR} 1+I+$ mice $(164.6 \pm 4.8$ vs $135.8 \pm 3.5, t=4.800, \mathrm{df}=138, p<0.0001)$. Moreover, firing rates in $\mathrm{PVcre} / \mathrm{NR} 1 \mathrm{fl} / \mathrm{fl}$ mice returned to baseline levels after $1 \mathrm{~h}$ of recording, whereas LTP in PVcre/ $\mathrm{NR} 1+/+$ mice was maintained $(147.4 \pm 2.7$ vs $115.1 \pm 3.5$, $t=7.300, \mathrm{df}=138, p<0.0001)$.

\section{Pharmacological Results}

We then tested two compounds, baclofen and MPEP, that share pharmacological specificity with therapeutic agents currently in clinical trials for the treatment of social deficits to determine whether either would ameliorate existing phenotypic differences between genotypes. Here we present results from social interaction, nest-building tests, ERPs, and spectral gamma power after administration of baclofen or MPEP.

Baclofen or MPEP was given to determine whether either compound would ameliorate deficits in self-care behavior previously observed in $\mathrm{PV}$ cre/NR1fl/fl mice. We administered each compound before exposure to the nest-building test. Data indicate that neither baclofen nor MPEP had an effect on the nest-building deficit (Figure 4a).

Data indicated that baclofen did not improve the social scores of PVcre/NR1fl/fl mice. Data also indicated that there was a significant main effect of drug in both groups when 
a

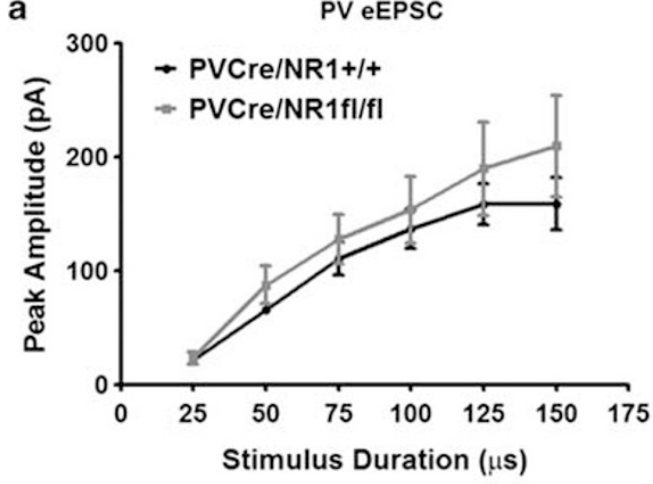

b PV sEPSC Frequency
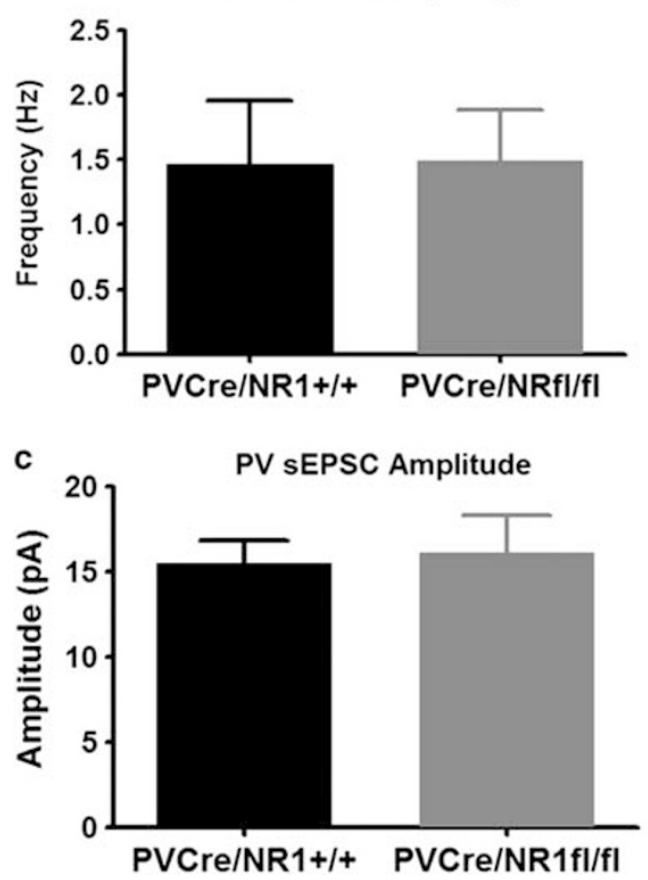

d
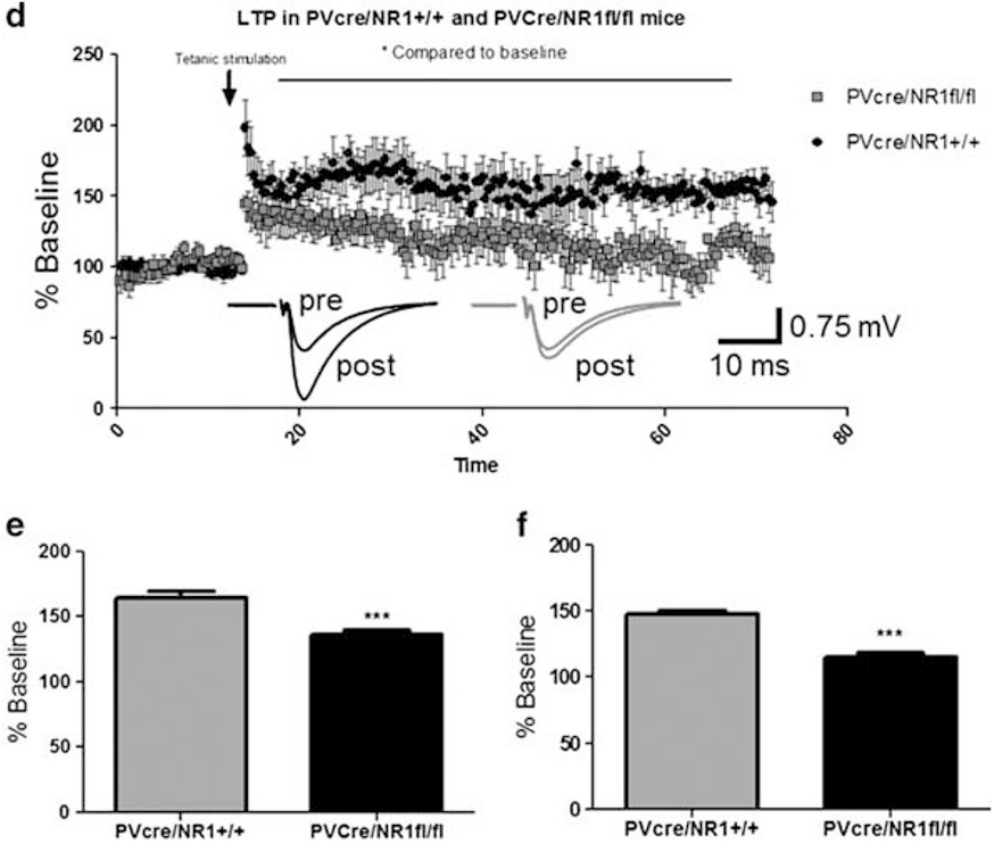

Figure 3 Ablation of NMDA receptors on PV interneurons does not affect membrane potential but reduces initiation and maintenance of long-term potentiation (LTP) after tetanus. (a) There is no difference between PVcre/NRI + / + and PVcre/NRI f/fl mice for the plot of evoked amplitude over time. (b, c) There is no difference in amplitude or frequency of spontaneous EPSCs in PVcre/NR I fl/f mice compared with controls. (d) Time course of LTP before and after tetanic stimulation. (e) Strength of LTP at induction is significantly reduced in PVcre/NRIfl/fl mice compared with controls $(t=4.800, \mathrm{df}=\mid 38$, $p<0.000 \mathrm{I}$ ). (f) Strength of LTP at I h after tetanic stimulation remains significantly lower in PVcre/NRI fl/fl mice compared with controls $(t=7.300, \mathrm{df}=\mid 38$, $p<0.000$ I). $* * * *<<0.001$.

given MPEP $(F=5.338, p=0.032)$, suggesting that MPEP further exacerbated the reduction in social scores of both PVcre/NR1fl/fl and PVcre/NR1 $+/+$ mice (Figure $4 \mathrm{~b}$ ). We then determined whether baclofen or MPEP would correct the N1 latency delay in PVcre/NR1fl/fl mice. There was no main effect of baclofen on the N1 latency delay of the ERP waveform (Figure 4c). Conversely, there was a significant main effect of MPEP on N1 latency in PVcre/NR1fl/fl mice $(\mathrm{F}=6.72, p=0.022)$, suggesting that MPEP further increased N1 latency across genotypes (Figure $4 \mathrm{~d}$ ). Because of MPEP effects on N1 latency and social behavior, we next determined whether there is a correlation between the two outcomes. Data indicate a negative correlation between N1 latency and social behavior in mice treated with MPEP, such that N1 latency decreases as the social index score increases $\left(r^{2}=0.3134, p=0.03\right)$, suggesting a potential predictive role for N1 latency as it relates to sociability (Figure 4e).
We next determined the effects of baclofen and MPEP on EEG spectral power. Similarly, we determined the extent to which either baclofen or MPEP would alter the observed correlations between baseline and evoked gamma power. Data indicate that baclofen normalized baseline gamma power in PVcre/NR1fl/fl mice (Figure 5a). When animals were given MPEP, baseline gamma power trended higher in both PVcre/NR1 $+/+$ and PVcre/NR1fl/fl mice $(\mathrm{F}=4.19$, $\mathrm{df}=1, p=0.052)$. As MPEP failed to reverse elevated baseline gamma power, data suggest that the mechanism of action for MPEP may require the presence of NMDARs on PV interneurons (Figure $5 \mathrm{~b}$ ). Data also indicate that the significant correlation between baseline and evoked gamma power remained in the presence of either baclofen $\left(r^{2}=0.3458, p=0.002\right)$ or $\operatorname{MPEP}\left(r^{2}=0.3960, p=0.0008\right)$, suggesting that baseline and evoked gamma power are not dissociable (Figure $5 c$ and $d$ ). 
a
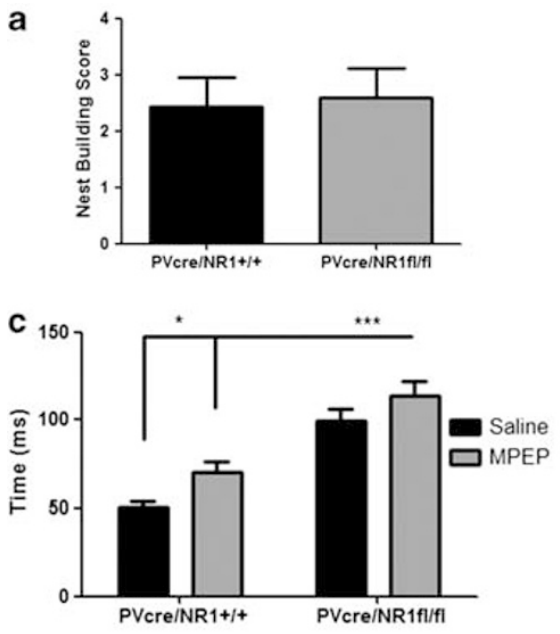

b
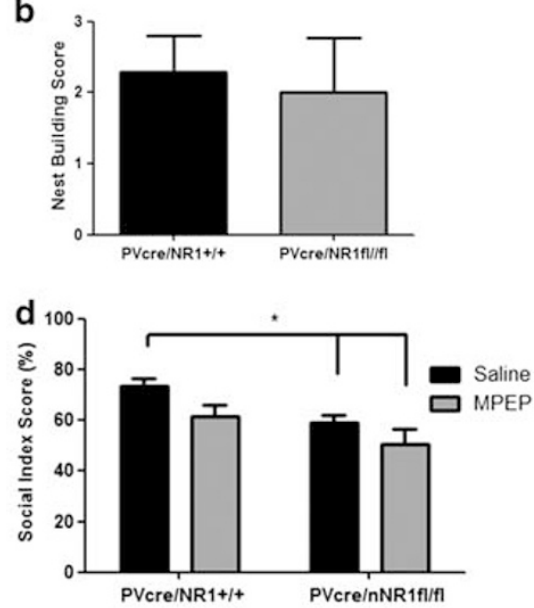

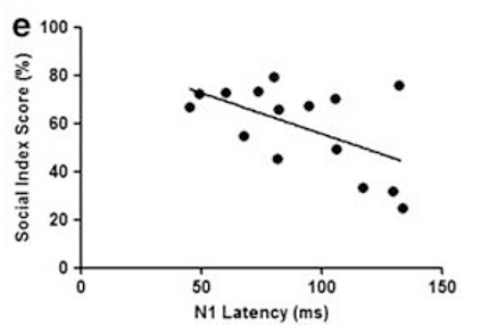

Figure 4 MPEP further impairs NI latency and sociability in animals with ablated NMDARs on PV-positive cells. (a, b) Nest building is not improved by (a) baclofen or (b) MPEP. (c) MPEP further significantly increases NI latency across both genotypes $(F=6.72, d f=1, p=0.02)$. (d) MPEP further significantly decreases sociability across genotypes $(F=5.33, d f=I, p=0.03)$. (e) Sociability and NI latency are significantly correlated in the presence of MPEP $\left(r^{2}=0.3 \mid 34, p=0.03\right)$. **** $P V_{c r e} / N R I f l / f l>P V_{c r e} / N R I^{+1+}, * M P E P>$ saline.

a

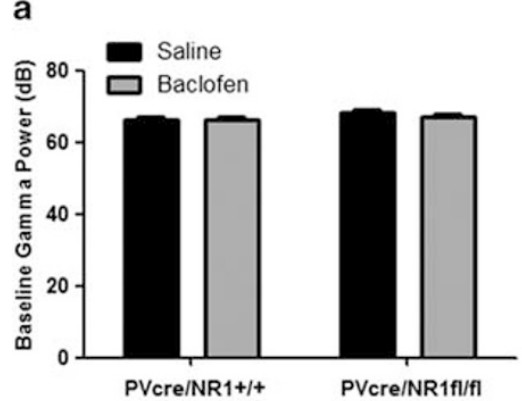

c

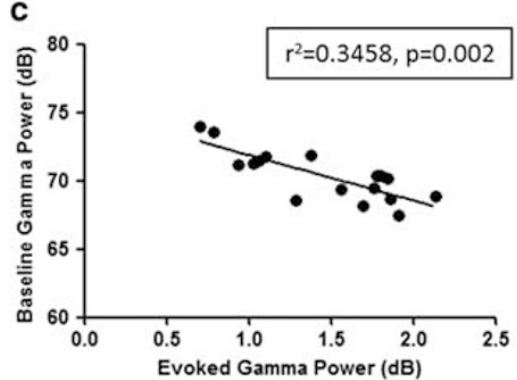

b

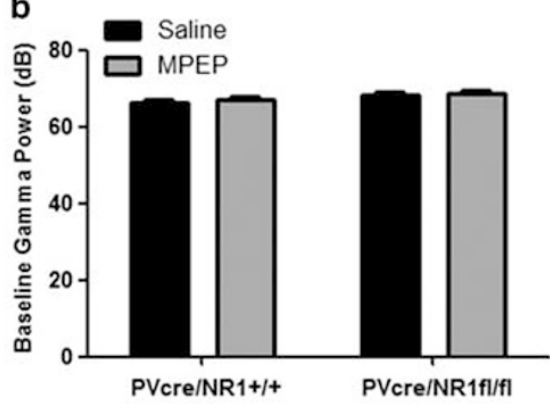

d

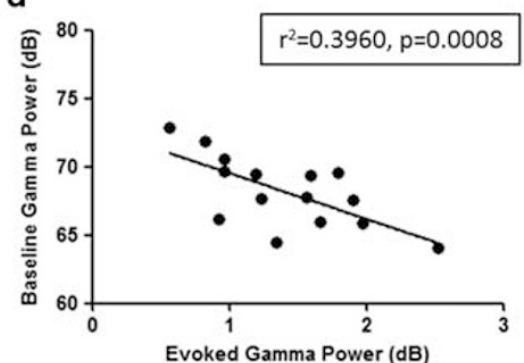

Figure 5 Baseline and evoked gamma power are not dissociable in the presence of either baclofen or MPEP following ablation of NMDARs on PV interneurons. (a) Baclofen normalizes baseline gamma power in PVcre/NRIfl/fl mice relative to PVcre/NRI $+/+$. (b) Following MPEP, there is a trend toward increased baseline gamma power in PVcre/NRIfl/f mice relative to control mice $(F=4.19, d f=I, p=0.052)$. (c, $d)$ Baseline and evoked gamma power are significantly correlated in the presence of $(c)$ baclofen $\left(r^{2}=0.3458, p=0.002\right)$ and (d) MPEP $\left(r^{2}=0.3960, p=0.0008\right)$.

\section{DISCUSSION}

The current study determined the profile of schizophrenia-like electrophysiological, cognitive, and behavioral deficits that are associated with NMDAR ablation on parvalbumin-containing interneurons and whether or not pharmacological agents that modulate downstream NMDAR or GABAergic signaling could reverse any observed deficits. Data indicate that phenotypic differences in self-care and sociability were the 
only behavioral abnormalities associated with lack of NMDARs on PV-containing interneurons. We also found that auditory ERP N1 latency was increased in PVcre/NR1fl/fl mice, in addition to reduced sociability, reflecting a more ASD-like phenotype. Data also revealed a diminution of LTP induction and maintenance in PVcre/NR1fl/fl slices, suggesting that NMDARs on interneurons are required for normal activity-dependent plasticity in neighboring pyramidal cells.

Following the determination of phenotypic differences between PVcre/NR1 $+/+$ and PVcre/NR1fl/fl mice, we administered two compounds that share pharmacological specificity with drugs currently in clinical trials to treat social deficits, the mGluR5 antagonist MPEP and the $\mathrm{GABA}_{\mathrm{B}}$ agonist baclofen, to determine whether either would reverse observed deficits. We found that neither baclofen nor MPEP reversed social deficits in PVcre/NR1fl/fl mice, but rather MPEP caused an overall reduction in this behavior. Moreover, MPEP significantly decreased sociability in PVcre/NR1 $+/+$ mice. We also found that baseline gamma power was significantly increased in PVcre/NR1fl/fl mice, whereas evoked gamma power was unaffected. Consistent with previous findings, there was a significant correlation of baseline and evoked gamma power. Our data also indicate that administration of baclofen but not MPEP normalized the elevated baseline gamma power in PVcre/ NR1fl/fl mice. However, MPEP but not baclofen caused a trend toward further increasing baseline gamma power in the same group. Moreover, the significant correlation between baseline and evoked gamma power remained following drug administration, supporting the hypothesis that evoked power is a function of the baseline state. Data also indicate that neither baclofen nor MPEP reverse the increased N1 latency or amplitude, but rather MPEP exacerbated further this deficit across genotypes.

Previous clinical studies have shown that M1 (N1 as measured with magnetoencephalography (MEG)) latency is shifted by $\sim 10 \%$ in ASD patients (Gandal et al, 2010; Roberts et al, 2010). The current study indicates that a comparable shift in latency occurs in the N40 (mouse N1) component in PVcre/NR1fl/fl mice. A study by Saunders et al (2013), using the same mouse model, showed that PVcre/NR1fl/fl mice not only had a shift in N1 latency, but also displayed reductions in pre-mating ultrasonic vocalizations (USVs). However, only social interaction was significantly correlated with N1 latency in that study. Similarly, previous studies suggest that low doses of NMDAR antagonists yield latency shifts, consistent with ASD, whereas higher doses result in schizophrenia-like changes in amplitude (Saunders et al, 2012). Taken together, these data suggest that low doses of NMDAR antagonists mimic PV-selective ablation of NR1, although yielding an ASD rather than a schizophrenia-like profile of ERPS.

We also report increased baseline gamma response in PVcre/NR1fl/fl mice. PVCre mice had higher baseline power in the $60-120 \mathrm{hz}$ gamma range than littermate PVcre/ $\mathrm{NR} 1+/+$ mice. These results are consistent with previous data demonstrating increased baseline gamma power only within a narrower frequency range $(36-44 \mathrm{hz}$ ) (Carlen et al, 2012). As such, the current study extends previous findings and demonstrates a phenotype that is broader than previously appreciated.
We evaluated the effect of NMDA receptor ablation in PV-containing interneurons on self-care using a nestbuilding paradigm. Lack of self-care is one of the many characteristics associated with negative symptoms in patients with schizophrenia (Siegel et al, 2006). As such, a deficit in nest building in mouse models could reflect a lack of self-care and therefore be interpreted as relevant to schizophrenia. A study using mice with deletion of NMDARs on PV- and Reelin-positive interneurons implicated the involvement of NMDARs on GABAergic cells in a variety of schizophrenia-related behaviors, including nest building (Belforte et al, 2010). Our data are consistent with these findings and add that NMDAR loss on $\mathrm{PV}$-positive interneurons alone is sufficient to cause this deficit.

Data in the current study also indicate that there is a reduction in sociability in $\mathrm{PVcre} / \mathrm{NR} 1 \mathrm{fl} / \mathrm{fl}$ mice. Blunted sociability is a negative symptom of schizophrenia (Siegel et al, 2006). Furthermore, reduced sociability is a core symptom of ASD (Roberts et al, 2010). These data again support the hypothesis of a potential role of impaired NMDAR function on PV-containing interneurons in the continuum of negative symptom phenotypes of schizophrenia and core features of ASD.

Deficits in cognition are also characteristic of patients with schizophrenia, as well as a subset of those with ASD (Arnold et al, 2000; Gur et al, 2001; Van Balkom et al, 2012). Two T-maze paradigms were used to determine whether working memory deficits observed in schizophrenia may be related to NMDAR dysfunction in PV interneurons. However, PVcre/NR1fl/fl mice performed better than PVcre/NR $1+I+$ on the continuous T-maze task and performed similarly to PVcre/NR1 $+/+$ on the discrete T-maze task, suggesting that selective dysfunction of NMDAR in PV interneurons alone is not sufficient to explain cognitive deficits in schizophrenia. Alternatively, PVcre/NR1fl/fl mice performed significantly better than their WT littermates, suggesting that selective deficits of NMDAR function on PV interneurons are inconsistent with the pathophysiology in schizophrenia. Although the current study found no evidence of working memory deficits in this model, data from our LTP studies suggest long-term memory storage may be compromised. Although neurons in PVcre/NR1fl/fl mice respond to tetanic stimulation, the response is not as robust as in $\mathrm{PVcre} / \mathrm{NR} 1+/+$ mice. Moreover, LTP begins to diminish after $30 \mathrm{~min}$ and returns to baseline in $1 \mathrm{~h}$, suggesting that the duration of LTP may be too unstable to allow for proper long-term encoding of information. Data in another model of NMDA ablation on $\mathrm{PV}$-positive interneurons support this conclusion (Belforte et al, 2010). Mice in the previous study performed significantly worse on contextual fear conditioning paradigms used to test long-term episodic memory. Together, these findings suggest PV-containing interneurons may contribute to long-term encoding or retrieval components of memory.

Taken together, deficits in nest building reflect a schizophrenia-like phenotype related to poor self-care, whereas increased N1 latency reflects an ASD-like electrophysiological phenotype. These measures were found coincident with social deficits common to both disorders. Together with previous findings, these findings suggest that (1) ASD 
and schizophrenia may exist on a continuum of disrupted excitability and inhibition (E/I), and (2) PV-selective alterations in NMDAR signaling more closely mimic core features of reduced sociability and vocalizations, as well as (3) the electrophysiological signature of increased N1 latency related to ASD.

Two compounds with distinct pharmacological profiles, the $\mathrm{GABA}_{\mathrm{B}}$ agonist baclofen and the mGluR5 antagonist MPEP, were administered to determine their effectiveness in ameliorating behavioral deficits in PVcre/NR1fl/fl mice. Although baclofen normalized increased baseline gamma power, it had no effect in social deficits, nest building, or N1 latency. These data, in combination with previous studies in constitutive NR1 hypomorphic mice, suggest that any behavioral benefits of $\mathrm{GABA}_{B}$ agonists likely occur via direct effects on hyperexcitability in pyramidal cells (Gandal et al, 2012). Therefore, these two studies in combination suggest that $\mathrm{GABA}_{\mathrm{B}}$ agonists are more likely to be a successful therapeutic strategy for schizophrenia than ASD. Conversely, MPEP exacerbated the changes related to observed behavior and EEG profile. MPEP further reduced sociability and increased latency in PVcre/NR1fl/fl mice. Moreover, MPEP increased N1 latency and reduced sociability in PVcre.NR1 $+I+$ mice. These two indices are negatively correlated in the presence of MPEP; as N1 latency increases, sociability decreases. This finding suggests that N1 latency may be a predictive biomarker for therapeutic effect related to social function. Although previous data from our laboratory and others found MPEP beneficial for core features of ASD, current data suggest beneficial effects of MPEP may require intact function of NMDAR on PV interneurons (Gandal et al, 2010). Specifically, MPEP binds to mGluR5 receptors to attenuate NMDAR-mediated glutamatergic activity. As PV-positive interneurons lack NMDA receptors in PVcre/NR1fl/fl mice, MPEP is only able to exert this effect on NMDARs in nonPV cell populations, thus further dampening excitation in the network. Furthermore, this augmentation in net effect on E/I balance appears to introduce a phenotype that more closely resembles schizophrenia, as evidenced by further reduction in sociability, and increased baseline gamma power. Complementary evidence from our laboratory supports this conclusion as MPEP ameliorates a subset of schizophrenia-related behaviors in a model where NMDARs are ablated from CaMKII $\alpha$-positive pyramidal cells (Tatard-Leitman et al, in review).

In summary, data in the current study add to the growing body of literature suggesting that disruptions of E/I balance underlie specific features of schizophrenia and ASD. Interestingly, PV cell-selective reduction of NR1 shown here are most consistent with ASD, whereas previous models that incorporate reductions of NR1 in pyramidal cells more closely model schizophrenia (Gandal et al, 2012). Similarly, pharmacological interventions that have been proposed for ASD, including both $\mathrm{GABA}_{\mathrm{B}}$ agonists and MGluR $_{5}$ antagonists, fail to remediate affected behaviors when NR1 is removed from PV interneurons (Burket et al, 2011; Mehta et al, 2011; Pacey et al, 2009; Silverman et al, 2012; Silverman et al, 2010). As such, data suggest that these pharmacological approaches may act through modulation of NR1 on PV interneurons in order to restore social function.

\section{FUNDING AND DISCLOSURE}

SJ Siegel reports grant support from Astellas, Eli Lilly, AstraZeneca, NuPathe, and Pfizer that is unrelated to the content of this paper, and consulting payments from Abbott, NuPathe, Merck, Sanofi, Boehringer Ingelheim, and Wyeth that are unrelated to this work. The other authors declare no conflict of interest.

\section{ACKNOWLEDGEMENTS}

Funding was provided by 5R01DA023210-04 (Siegel), 5R01MH074672 -04 (SJ Siegel), 1P50MH096891-01 (RE Gur), T32MH019112 to RE (Gur), as well as Developmental funds from the University of Pennsylvania (SJ Siegel).

\section{REFERENCES}

Amann LC, Halene TB, Ehrlichman RS, Luminais SN, Ma N, Abel T et al (2009). Chronic ketamine impairs fear conditioning and produces long-lasting reductions in auditory evoked potentials. Neurobiol Dis 35: 311-317.

Arnold LE, Aman MG, Martin A, Collier-Crespin A, Vitiello B, Tierney $\mathrm{E}$ et al (2000). Assessment in multisite randomized clinical trials of patients with autistic disorder: the Autism RUPP Network. Research Units on Pediatric Psychopharmacology. J Autism Dev Disord 30: 99-111.

Belforte JE, Zsiros V, Sklar ER, Jiang Z, Yu G, Li Y et al (2010). Postnatal NMDA receptor ablation in corticolimbic interneurons confers schizophrenia-like phenotypes. Nat Neurosci 13: 76-83.

Boutros NN, Brockhaus-Dumke A, Gjini K, Vedeniapin A, Elfakhani M, Burroughs S et al (2009). Sensory-gating deficit of the N100 mid-latency auditory evoked potential in medicated schizophrenia patients. Schizophr Res 113: 339-346.

Burket JA, Herndon AL, Winebarger EE, Jacome LF, Deutsch SI (2011). Complex effects of mGluR5 antagonism on sociability and stereotypic behaviors in mice: possible implications for the pharmacotherapy of autism spectrum disorders. Brain Res Bull 86: 152-158.

Capecchi MR (1989). Altering the genome by homologous recombination. Science 244: 1288-1292.

Carlen M, Meletis K, Siegle JH, Cardin JA, Futai K, VierlingClaassen D et al (2012). A critical role for NMDA receptors in parvalbumin interneurons for gamma rhythm induction and behavior. Mol Psychiatry 17: 537-548.

Carlson GC, Talbot K, Halene TB, Gandal MJ, Kazi HA, Schlosser L et al (2011). Dysbindin-1 mutant mice implicate reduced fastphasic inhibition as a final common disease mechanism in schizophrenia. Proc Natl Acad Sci USA 108: E962-E970.

Connolly PM, Maxwell C, Liang Y, Kahn JB, Kanes SJ, Abel T et al (2004). The effects of ketamine vary among inbred mouse strains and mimic schizophrenia for the P80, but not P20 or N40 auditory ERP components. Neurochem Res 29: 1179-1188.

Deacon RM (2006). Assessing nest building in mice. Nat Protoc 1: 1117-1119.

Deacon RM, Rawlins JN (2006). T-maze alternation in the rodent. Nat Protoc 1: 7-12.

Delorme A, Makeig S (2004). EEGLAB: an open source toolbox for analysis of single-trial EEG dynamics including independent component analysis. J Neurosci Methods 134: 9-21.

Ehrlichman RS, Gandal MJ, Maxwell CR, Lazarewicz MT, Finkel LH, Contreras D et al (2009). N-methyl-d-aspartic acid receptor antagonist-induced frequency oscillations in mice recreate pattern of electrophysiological deficits in schizophrenia. Neuroscience 158: 705-712. 
Ehrlichman RS, Maxwell CR, Majumdar S, Siegel SJ (2008). Deviance-elicited changes in event-related potentials are attenuated by ketamine in mice. J Cogn Neurosci 20: 1403-1414.

Featherstone RE, Liang Y, Saunders JA, Tatard-Leitman VM, Ehrlichman RS, Siegel SJ (2012). Subchronic ketamine treatment leads to permanent changes in EEG, cognition and the astrocytic glutamate transporter EAAT2 in mice. Neurobiol Dis 47: 338-346.

Featherstone RE, MT-L V, Suh JD, Lin R, Lucki I, Siegel SJ (2013). Electrophysiological and behavioral responses to ketamine in mice with reduced Akt1 expression. Psychopharmacology (Berl) 227: 639-649.

Gandal MJ, Edgar JC, Ehrlichman RS, Mehta M, Roberts TP, Siegel SJ (2010). Validating gamma oscillations and delayed auditory responses as translational biomarkers of autism. Biol Psychiatry 68: $1100-1106$.

Gandal MJ, Ehrlichman RS, Rudnick ND, Siegel SJ (2008). A novel electrophysiological model of chemotherapy-induced cognitive impairments in mice. Neuroscience 157: 95-104.

Gandal MJ SJ, Klook K, Tatard-Leitman VM, Liang Y, Thieu T, Ortinski PI et al (2012). GABAB-mediated rescue of altered excitatory-inhibitory balance, gamma synchrony, and behavioral deficits following constitutive NMDAR-hypofunction. Transl Psychiatry 2: e142.

Gur RC, Ragland JD, Moberg PJ, Bilker WB, Kohler C, Siegel SJ et al (2001). Computerized neurocognitive scanning: II. The profile of schizophrenia. Neuropsychopharmacology 25: 777-788.

Halene TB, Ehrlichman RS, Liang Y, Christian EP, Jonak GJ, Gur TL et al (2009). Assessment of NMDA receptor NR1 subunit hypofunction in mice as a model for schizophrenia. Genes Brain Behav 8: 661-675.

Hippenmeyer S, Vrieseling E, Sigrist M, Portmann T, Laengle C, Ladle DR et al (2005). A developmental switch in the response of DRG neurons to ETS transcription factor signaling. PLoS Biol 3: e159.

Hugdahl K, Loberg EM, Nygard M (2009). Left temporal lobe structural and functional abnormality underlying auditory hallucinations in schizophrenia. Front Neurosci 3: 34-45.

Javitt DC, Zylberman I, Zukin SR, Heresco-Levy U, Lindenmayer JP (1994). Amelioration of negative symptoms in schizophrenia by glycine. Am J Psychiatry 151: 1234-1236.

Krystal JH, Karper LP, Seibyl JP, Freeman GK, Delaney R, Bremner JD et al (1994). Subanesthetic effects of the noncompetitive NMDA antagonist, ketamine, in humans. Psychotomimetic, perceptual, cognitive, and neuroendocrine responses. Arch Gen Psychiatry 51: 199-214.

Lahti AC, Koffel B, LaPorte D, Tamminga CA (1995). Subanesthetic doses of ketamine stimulate psychosis in schizophrenia. Neuropsychopharmacology 13: 9-19.

Lazarewicz MT, Ehrlichman RS, Maxwell CR, Gandal MJ, Finkel LH, Siegel SJ (2010). Ketamine modulates theta and gamma oscillations. J Cogn Neurosci 22: 1452-1464.
Maxwell CR, Ehrlichman RS, Liang Y, Trief D, Kanes SJ, Karp J et al (2006). Ketamine produces lasting disruptions in encoding of sensory stimuli. J Pharmacol Exp Ther 316: 315-324.

Mehta MV, Gandal MJ, Siegel SJ (2011). mGluR5-antagonist mediated reversal of elevated stereotyped, repetitive behaviors in the VPA model of autism. PLoS One 6: e26077.

Pacey LK, Heximer SP, Hampson DR (2009). Increased GABA(B) receptor-mediated signaling reduces the susceptibility of fragile $\mathrm{X}$ knockout mice to audiogenic seizures. Mol Pharmacol 76: $18-24$.

Roberts TP, Khan SY, Rey M, Monroe JF, Cannon K, Blaskey L et al (2010). MEG detection of delayed auditory evoked responses in autism spectrum disorders: towards an imaging biomarker for autism. Autism Res 3: 8-18.

Sankoorikal GM, Kaercher KA, Boon CJ, Lee JK, Brodkin ES (2006). A mouse model system for genetic analysis of sociability: C57BL/6J versus BALB/cJ inbred mouse strains. Biol Psychiatry 59: 415-423.

Saunders JA, Gandal MJ, Roberts TP, Siegel SJ (2012). NMDA antagonist MK801 recreates auditory electrophysiology disruption present in autism and other neurodevelopmental disorders. Behav Brain Res 234: 233-237.

Saunders JA, Tatard-Leitman VM, Suh J, Billingslea EN, Roberts TP, Siegel SJ (2013). Knockout of NMDA receptors in parvalbumin interneurons recreates autism-like phenotypes. Autism Res 6: 69-77.

Siegel SJ, Irani F, Brensinger CM, Kohler CG, Bilker WB, Ragland JD et al (2006). Prognostic variables at intake and long-term level of function in schizophrenia. Am J Psychiatry 163: 433-441.

Silverman JL, Smith DG, Rizzo SJ, Karras MN, Turner SM, Tolu SS et al (2012). Negative allosteric modulation of the mGluR5 receptor reduces repetitive behaviors and rescues social deficits in mouse models of autism. Sci Transl Med 4: 131ra151.

Silverman JL, Tolu SS, Barkan CL, Crawley JN (2010). Repetitive self-grooming behavior in the BTBR mouse model of autism is blocked by the mGluR5 antagonist MPEP. Neuropsychopharmacology 35: 976-989.

Tsien JZ, Chen DF, Gerber D, Tom C, Mercer EH, Anderson DJ et al (1996). Subregion- and cell type-restricted gene knockout in mouse brain. Cell 87: 1317-1326.

Turetsky BI, Greenwood TA, Olincy A, Radant AD, Braff DL, Cadenhead KS et al (2008). Abnormal auditory N100 amplitude: a heritable endophenotype in first-degree relatives of schizophrenia probands. Biol Psychiatry 64: 1051-1059.

Van Balkom ID, Vuijk PJ, Franssens M, Hoek HW, Hennekam RC (2012). Development, cognition, and behaviour in Pitt-Hopkins syndrome. Dev Med Child Neurol 54: 925-931.

Winterer G, Ziller M, Dorn H, Frick K, Mulert C, Wuebben Y et al (2000). Schizophrenia: reduced signal-to-noise ratio and impaired phase-locking during information processing. Clin Neurophysiol 111: 837-849.

Yizhar O, Fenno LE, Prigge M, Schneider F, Davidson TJ, O'Shea DJ et al (2011). Neocortical excitation/inhibition balance in information processing and social dysfunction. Nature 477: 171-178.

Supplementary Information accompanies the paper on the Neuropsychopharmacology website (http://www.nature.com/npp) 